Int. J. of Electronics Engineering and Applications, Vol. 7, NNo. 2, 2019

\title{
A SINGLE SOURCE CASCADED MULTILEVEL INVERTER
}

\author{
Poornima D, Bharath Kumar M R and Andrew Mathew Domnic F
}

\begin{abstract}
The power rating at industrial equipment is constantly hiking. Now it is reached to the megawatt level, corresponding to the medium-voltage $(2.3,3.3,4.16$, or $6.9 \mathrm{kV})$ network. It is hard to connect a single power semiconductor switch directly to medium voltage grids. For this, multilevel inverters have emerged as the solution for working with higher voltage levels. For applications with voltage higher than $6 \mathrm{kV}$, cascaded H bridge multilevel inverters are commonly used. To generate separated voltage sources a multi-phase transformer is usually applied to generate these DC sources from a three phase AC power source. The input current of inverter cells with specific phase shift due to multi-phase transformer can lower the high frequency harmonics, mass secondary wires and connection will definitely not only increase the size and weight of the equipment, but also complicate the wiring. In order to overcome all these drawbacks, a new cascaded multilevel inverter is proposed. The new topology has a modular structure like H-bridge topology and is easy to be extended to higher level. Proposed topology can greatly simplify the system wiring, just requiring very low space. Each cell (H-bridge cell) can be regarded as containing a boostconverter, a low capacitance DC capacitor and a half bridge inverter. MATLAB simulations are also included to verify the performance and functioning of the proposed systemalong with a hardware design.
\end{abstract}

Keywords: H-bridge cell, multilevel inverters, boostconverter, halfbridge inverter, harmonics, multiphase transformer, DC capacitor.

Reference to this paper should be made as follows: Poornima D, Bharath Kumar M R, Andrew Mathew Domnic F, (2019), “A Single Source Cascaded Multilevel Inverter" Int. J. Electronics Engineering and Applications, Vol. 7, No. 2, pp.37-46

\section{Biographicalnotes:}

Poornima D: Assistant Professor, Nehru institute of Engineering \& Techonology, Coimbatore, Tamilnadu.

Bharath Kumar M R: Pre final year, Nehru institute of Engineering \& Techonology, Coimbatore, Tamilnadu.

Andrew Mathew Domnic: F33Pre final year, Nehru institute of Engineering \& Techonology, Coimbatore, Tamilnadu. 


\section{Poornima D}

\section{INTRODUCTION}

A multiphase transformer is used to generate separated voltage sources from a three phase AC supply. For applications greater than $6 \mathrm{kV} \mathrm{H}-$ Bridge inverters are used but in this case, lots of isolated voltage sources are needed. The concept of utilizing multilevel voltages was founded around thirty years ago [13]. Advantages of this was good quality of power, low switching losses, high voltage capability and good electromagnetic compatibility. The main disadvantages of this technique are that a larger number of switching semiconductors are required for lower-voltage systems and the small voltage steps must be supplied on the dc side either by a capacitor bank or isolated voltage sources. The first topology introduced was the series H-bridge design [1]. This was followed by the diode- clamped [2-4] converter which utilized a bank of series capacitors. A later invention [5] detailed the flying capacitor design in which the capacitors were floating rather than series-connected. Another multilevel design involves parallel connection of inverter phases through inter-phase reactors [6]. In this design, the semiconductors block the entire dc voltage, but share the load current. Several combinational designs have also emerged [7] some involving cascading the fundamental topologies [8-12]. These designs can create higher power quality for a given number of semiconductor devices. This is possible due to the multiplying effect of the different voltage levels.

\section{RELATED WORK}

A single-phase structure of an m-level cascaded inverter is illustrated in [Figure 1]. Each separate dc source (SDCS) is connected to a single-phase full-bridge, or H-bridge, inverter [14-15]. Each inverter level can generate three different voltage outputs, $+\mathrm{Vdc}, 0$, and $-\mathrm{Vdc}$ by connecting the $\mathrm{dc}$ source to the ac output by different combinations of the four switches, S1, S2, S3, and S4. To obtain $+\mathrm{Vdc}$, switches $\mathrm{S} 1$ and $\mathrm{S} 4$ are turned on, whereas -Vdc can be obtained by turning on switches $\mathrm{S} 2$ and S3. By turning on S1 and S2 or S3 and S4, the output voltage is 0 . The ac outputs of each of the different full-bridge inverter levels are connected in series such that the synthesized voltage waveform is the sum of the inverter outputs. The number of output phase voltage levels $\mathrm{m}$ in a cascade inverter is defined by $\mathrm{m}=2 \mathrm{~s}+1$, where $\mathrm{s}$ is the number of separate dc sources. An example phase voltage waveform for an 11-level cascaded H-bridge inverter with 5 SDCSs and 5 full bridges is shown in [Figure 2]. The phase voltage

$\mathrm{van}=\mathrm{va} 1+\mathrm{va} 2+\mathrm{va} 3+\mathrm{va} 4+\mathrm{va} 5$

For a stepped waveform such as the one depicted in [Figure 4] with 5 steps, the Fourier Transform for this waveform follows:

$\mathrm{V}(\omega \mathrm{t})=\operatorname{Vdc} \sum[\cos (\mathrm{n} \theta 1)+\cos (\mathrm{n} \theta 2)+\ldots \ldots . .+\cos (\mathrm{n} \theta \mathrm{s})] \sin (\mathrm{n} \omega \mathrm{t})$, Where $\mathrm{n}=1,3,5$, 7 

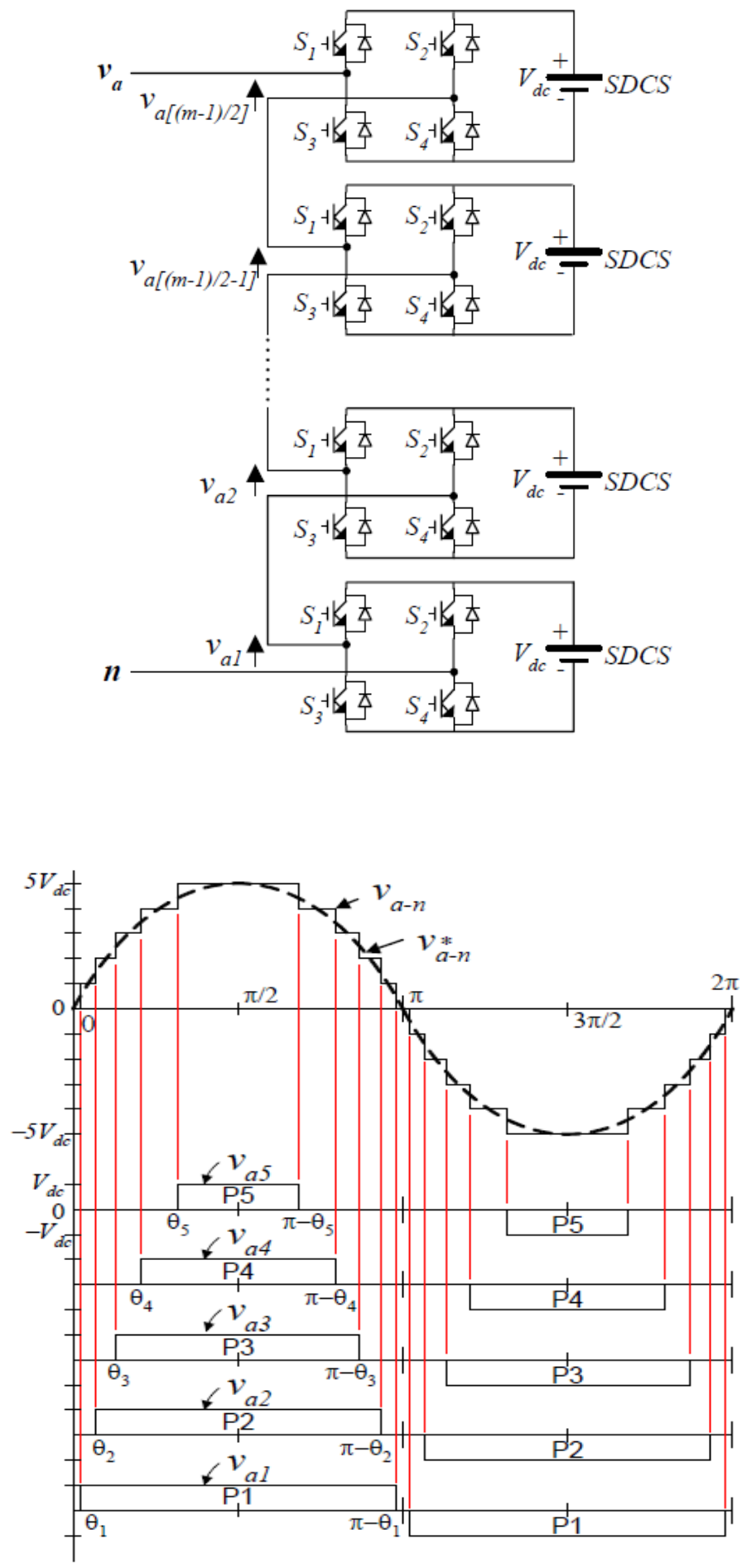

Figure.2. Output phase voltage waveform of an 11 -level cascade inverter

From (1), the magnitudes of the Fourier coefficients when normalized with respect to Vdc are as follows:

$H(n)=[\cos (n \theta 1)+\cos (n \theta 2)+\ldots \ldots .+\cos (n \theta s)]$, Where $n=1,3,5,7 \ldots$ (3)

The conducting angles, $\theta 1, \theta 2 \ldots \theta \mathrm{s}$, can be chosen such that the voltage total harmonic distortion is a minimum. Generally, these angles are chosen so that predominant lower frequency harmonics, 5th, 7th, 11th, and 13 th, harmonics are eliminated. 


\section{Poornima D}

\section{PROPOSED WORK}

The below given is the circuit diagram of the inverter. each inverter cell is cascaded with the other and the output is connected to the motor load.

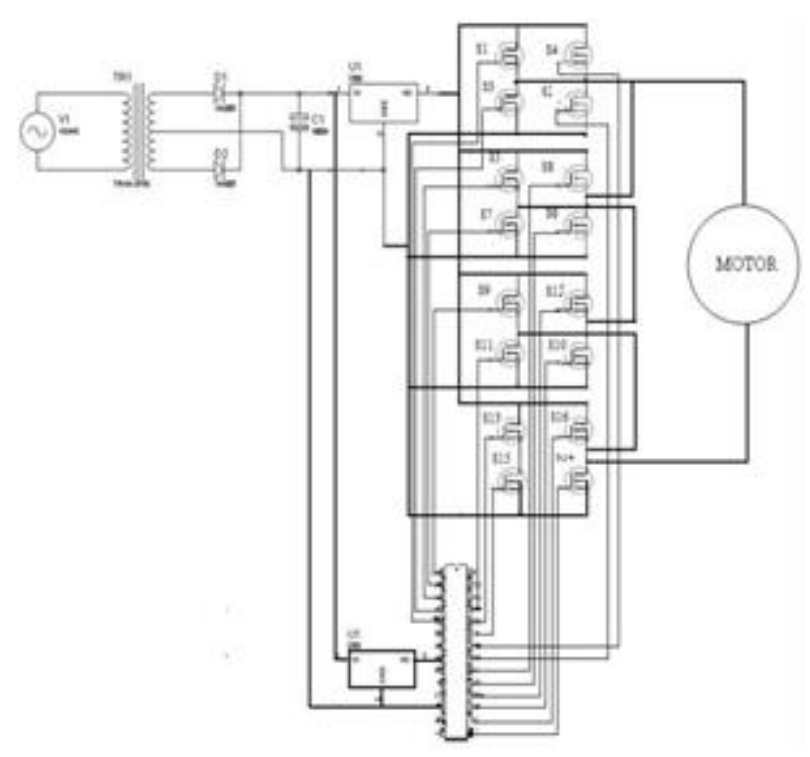

Figure 3: Circuit Diagram of the inverter

[Figure.3]. shows a circuit diagram of the multilevel inverter. The model output voltage waveform of nine-level cascaded multilevel inverter is shown in the [Figure 4].

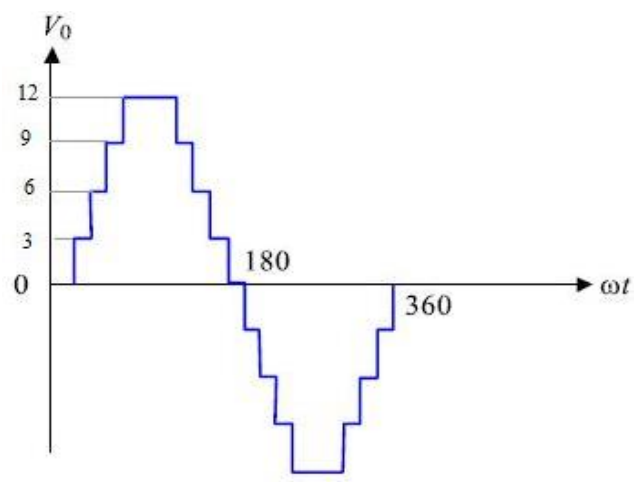

Figure 4. Model output voltage of the inverter

The maximum output phase voltage is given as $25 \mathrm{~V}$ p-p. The steps to synthesize the nine-level voltage waveforms are as follows. 
1. For an output voltage level $\mathrm{V} 0=0$, no switch in the $\mathrm{H}$-bridges are turned on.

2. For an output voltage level $\mathrm{V} 0=3 \mathrm{~V}$, turn on the switches $\mathrm{S} 1, \mathrm{~S} 2, \mathrm{~S} 8, \mathrm{~S} 12, \mathrm{~S} 16$.

3. For an output voltage $\mathrm{V} 0=6 \mathrm{~V}$, turn on all the switches as mentioned in step 2 and $\mathrm{S} 7$.

4. For an output voltage level $\mathrm{V} 0=9 \mathrm{~V}$, turn on all the switches in the step 3 and $\mathrm{S} 11$.

5. For an output voltage level $\mathrm{V} 0=12 \mathrm{~V}$, turn on all the switches in the step 3 and S15. Condition 1 means the switch is on and 0 means the switch is off. Each switch is turned on only once per cycle and therefore reduces switching losses.

\section{OUR IDEA}

Fourier series of the quarter-wave symmetric $\mathrm{S} \mathrm{H}$ - bridge multilevel inverter output waveform is written as given in equation (2) in which $\theta_{\mathrm{s}}$ are the optimized switching angles, which must satisfy the following condition

$$
\theta_{1}<\theta_{2}<\cdots<\theta_{\mathrm{S}}<\pi / 2
$$

The method to solve the optimized harmonic switching angles will be explained in this section. From equation (1), the harmonic components in the waveform can described as follows:

1. The amplitude of dc component equals zero.

2. The amplitude of all odd harmonic components including fundamental one, are given by

$$
\mathrm{H}(\mathrm{n})=\frac{4 V d c}{\pi n} \sum_{K}^{8}[\cos n \theta k]
$$

3. The amplitude of all even harmonics equal zero. Thus, only the odd harmonics in the quarterwave symmetric multilevel waveform need to be eliminated. The switching angles of the waveform will be adjusted to get the lowest THD in the output voltage

$$
H(n)=\frac{4}{\pi n}\left[\cos \left(n \theta_{1}\right)+\cos \left(n \theta_{2}\right)+\cos \left(n \theta_{3}\right)+\cos \left(n \theta_{4}\right)\right],---(6)
$$

If needed to control the peak value of the output voltage to be $\mathrm{V} 1$ and eliminate the fifth and seventh order harmonics, the modulation index is given by $\mathrm{M}=\pi \mathrm{V} 1 / 4 \mathrm{~V}_{\mathrm{dc}}$ the resulting harmonic equations are

$$
\begin{aligned}
& \frac{4 V d c}{\pi n}\left[\cos \left(\theta_{1}\right)+\cos \left(\theta_{2}\right)+\cos \left(\theta_{3}\right)+\cos \left(\theta_{4}\right)\right]=\mathrm{V}_{1} \\
& {\left[\cos \left(5 \theta_{1}\right)+\cos \left(5 \theta_{2}\right)+\cos \left(5 \theta_{3}\right)+\cos \left(5 \theta_{4}\right)\right]=0} \\
& {\left[\cos \left(7 \theta_{1}\right)+\cos \left(7 \theta_{2}\right)+\cos \left(7 \theta_{3}\right)+\cos \left(7 \theta_{4}\right)\right]=0}
\end{aligned}
$$

And the first equation can be rewritten as

$$
\left[\cos \left(\theta_{1}\right)+\cos \left(\theta_{2}\right)+\cos \left(\theta_{3}\right)+\cos \left(\theta_{4}\right)\right]=\mathrm{M}
$$

Each H-bridge inverter unit has a conduction angle which is calculated to minimize the harmonic components. The conduction angles are the factors determining the amplitude of the harmonic components. In nine level inverter four dc sources are needed so that the dc voltage levels are chosen so as not to generate the fifth and seventh order harmonics while achieving the desired 


\section{Poornima D}

fundamental voltage. This is a system of three simultaneous equations with four unknowns' $\theta 1, \theta 2$, $\theta 3$ and $\theta 4$. These values are found by solving the simultaneous equations (7-9).

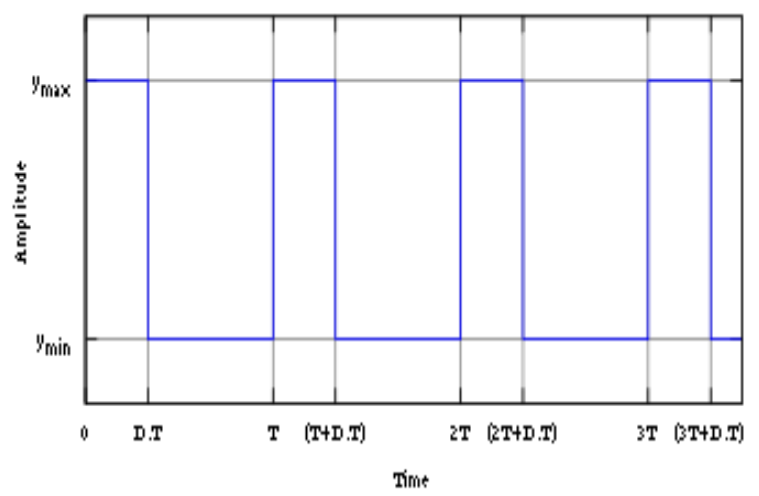

Figure.5. A pulse wave, showing the definitions of $y_{\min }, y_{\max }$ and D

Pulse-width modulation uses a rectangular pulse wave whose pulse width is modulated resulting in the variation of the average value of the waveform as shown in the fig 5. If we consider a pulse waveform $f(t)$ with a low value $y_{\min }$, a high value $y_{\max }$ and a duty cycle $\mathrm{D}$ (see figure 1), the average value of the waveform is given by:

$$
\mathrm{y}=\frac{1}{T} \int_{0}^{T} f(t) d t
$$

As $f(t)$ is a pulse wave, its value is $y_{\max }$ for $0<\mathrm{t}<\mathrm{D}$. T and $y_{\min }$ for D. T $<\mathrm{t}<\mathrm{T}$. The above expression then becomes:

$$
\begin{gathered}
\mathrm{y}=\frac{1}{T}\left(\int_{0}^{D T} y \max d t+\int_{D T}^{T} \mathrm{ymin} d t\right) \\
=\frac{D \cdot T \cdot y \max +T(1-D) y \min }{T} \\
=\mathrm{D} \cdot \mathrm{y}_{\max }+(1-\mathrm{D}) \mathrm{y}_{\min }--
\end{gathered}
$$

This latter expression can be fairly simplified in many cases where $y_{\min }=0$ as $\mathrm{y}=\mathrm{D}$. $\mathrm{y}_{\max }$. From this, it is obvious that the average value of the signal (y) is directly dependent on the duty cycle D.

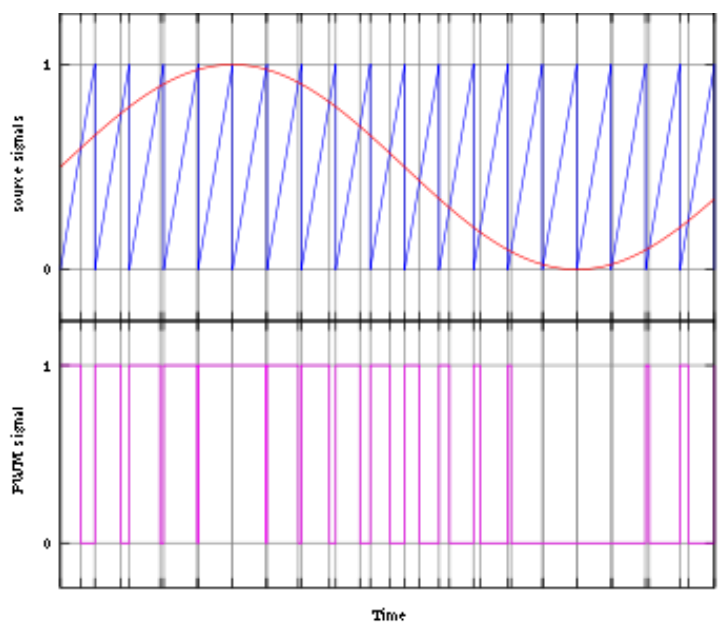

Figure 6: A simple method to generate the PWM pulse train 
The simplest way to generate a PWM signal is the interceptive method, which requires only a saw tooth or a triangle waveform (easily generated using a simple oscillator) and a comparator. When the value of the reference signal (the red sine wave in figure 7) is more than the modulation waveform (blue), the PWM signal (magenta) is in the high state, otherwise it is in the low state corresponding to a given signal intersective PWM: the signal (here the red sine wave) is compared with a saw tooth waveform (blue). When the latter is less than the former, the PWM signal (magenta) is in high state (1). Otherwise it is in the low state (0) as show on [Figure.6].

\section{WORKING AND OPERATION}

The load is an AC motor of induction motor with of 15 watts, $230 \mathrm{~V}, 50 \mathrm{~Hz}$. A $4 \mathrm{H}$-bridge inverter cells are used. These also act as a boost converter. One aspect which sets the cascaded H-bridge apart from other multilevel inverters is the capability of utilizing different DC voltages on the individual H-bridge cells which results in splitting the power conversion amongst higher-voltage lower-frequency and lower-voltage higher-frequency inverters. A prototype of nine level cascaded multilevel inverter has been fabricated and tested. The switching signals for the model are generated from AT mega 8microcontroller. The voltages to the components are regulated using 7805 IC. The driver circuits are also used to give pulse for switches in the power circuit. The power circuit is isolated by using opto-coupler circuit (MC3023\&PC817). Opto-couplers also known as optoisolators provide optical isolation and coupling between control circuit and power circuit, creating physical and electrical isolation signal coupling between them. Optocouplers which can be assembled using traditional semiconductor packages contain a light emitting diode and photo sensitive semiconductor devices in the same housing.

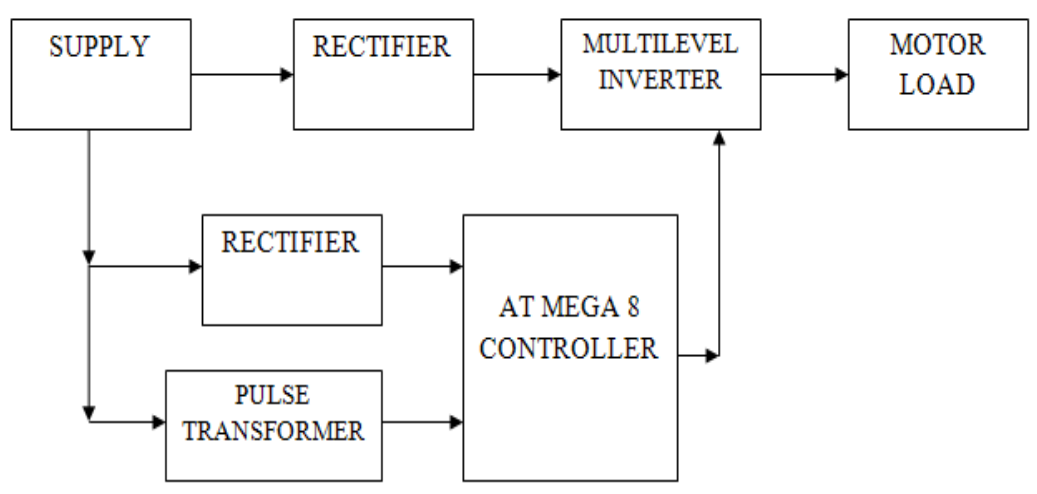

Figure 7: Block Diagram of cascaded multilevel inverter with single DC source

\section{BLOCK DIAGRAM DESCRIPTION}

An AC supply voltage $230 \mathrm{~V} 50 \mathrm{~Hz}$ is given as the input supply. This supply, with the help of proper rectification is given to all the components. Here, a Full wave rectifiers and bridge rectifiers are used for rectifying the AC supply voltage to obtain DC. The nine level cascade multilevel inverter consists of $4 \mathrm{H}$-bridge inverters. Totally 16 switches are used. IRF540 MOSFET's are used as switches. Along with this a $230-5 \mathrm{~V}, 50 \mathrm{~Hz}, 100 \mathrm{~mA}$, pulse transformer is used to produce the reference waveform for the controller. 

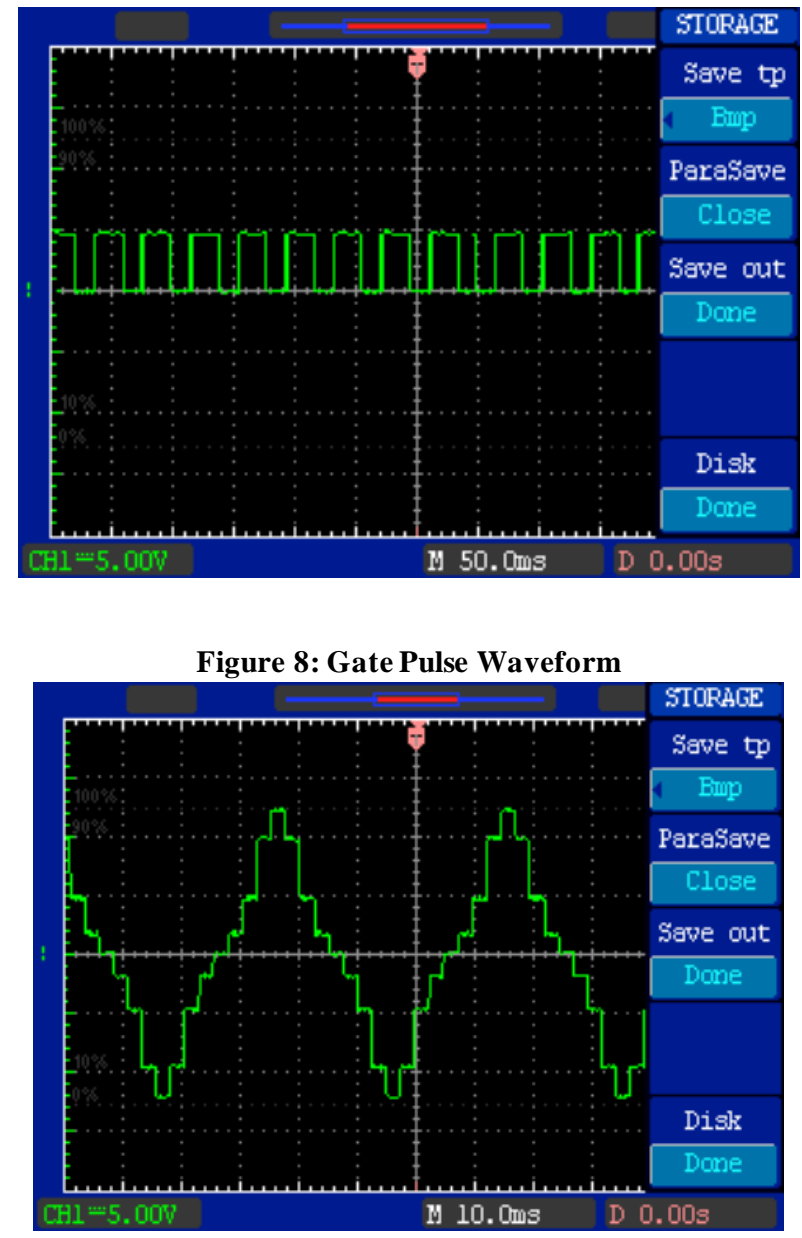

Figure 9: Output Waveform of inverter

\section{HARDWARE DESIGN}

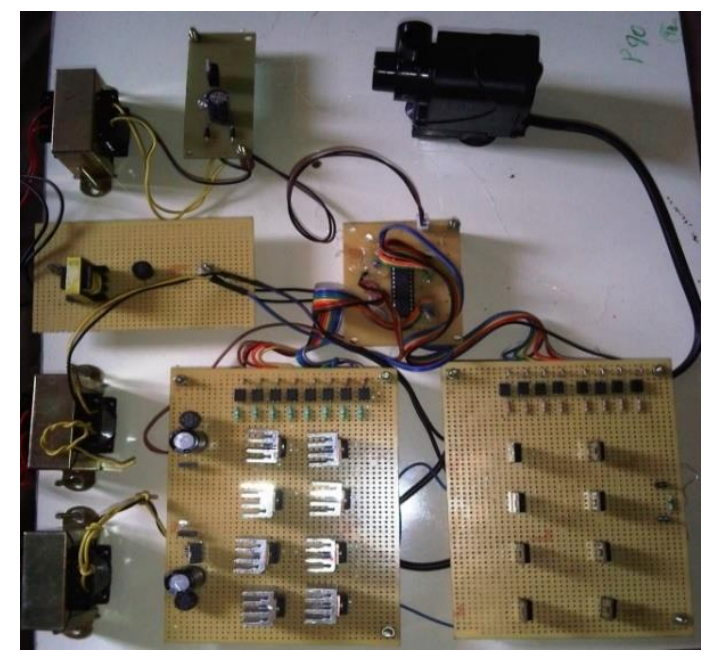

Figure.10. Hardware circuit

The above [Figure.10] shows the hardware circuit of the inverter. Four $\mathrm{H}$ bridge inverters are used for a single phase. A total of 16 switches are used. A 9 level inverter has been modeled. A low 
power induction motor has been used as the load. This is the circuit of a single inverter bridge. Four IGBT switches are used to obtain the output voltage. The voltage depends on the switching times of the IGBT. There is a charging capacitor $\mathrm{C}$ and a source resistance $\mathrm{R}$. the output is taken from 2 to cascade it with the next inverter bridge. This is the circuit of the pulse generator for a single phase. A sine wave of $50 \mathrm{~Hz}$ is compared with a pulsating DC of $50 \mathrm{~Hz}$ and if the result is positive output is one and if negative the output is zero. The microcontroller has been programmed to produce the correct phase shifted gate pulses.

\section{CONCLUSION}

This project presents an important change in the cascaded multilevel inverters by using a single source. Proposed circuit dispenses with masses of isolated DC voltage sources which are required in conventional cascaded inverters. Simulation had been done for 3 phases in phase I of the project and the hardware for a single phase has been developed in the second phase. This can be used in voltage regulation, audio effects and amplifications, Telecommunication and power delivery. 


\section{REFERENCES}

[1] Masakazu Muneshima, Hui Zhang, Shohei Tokunaga,Shota Urushibata, Takashi Kodama, and Masakatsu Nomura:" A New Boost Type Cascaded Inverter With Single DC Source", 8th International Conference on Power Electronics - ECCE Asia,pp.1719-1725 (2011)

[2] Maruthu Pandi Perumal,Devarajan Nanjudapan: "Performance Enhancement Of Embedded System Ba sed Multilevel Inverter Using Genetic Algorithm”, Journal Of ElectricalEngineering, Vol. 62, No. 4, 2011, 190-198

[3] J. Wen, and K. M. Smedley: "Synthesis of Multilevel Converters Based on Single-and orThree-Phase Converter Building Blocks", IEEE Trans. Power. Electron. Vol.23, No.3, pp.1247-1256(2008).

[4] P. W. Hammond: "A new Approach to enhance Power Quality for Medium Voltage AC Drives", IEEE Trans. Ind. Appl., Vol.33, No.1, pp.202-208(1997)

[5] A. Nabae, I. Takahashi, and H. Akagi: "A New Neutral- Point-Clamped PWM Inverter, and Applications ", IEEE Trans. Ind. Appl., Vol.1 A-17, No.5, pp.518-523(1981)

[6] J. Rodriguez, J. Lai, and F. Z. Peng: "Multilevel Inverters: A Survey of Topologies, Controls, and Applications ", IEEE Trans. Ind. Appl., Vol.49, No.4,pp.724-738(2002)

[7] F. Z. Peng, W. Qian and D. Cao: "Recent Advances in Multilevel Converter/Inverter Topologies and Applications", The 2010 International Power Electronics Conference, pp.492-501.

[8] F. Z. Peng: "A Genera lized Multilevel Inverter Topology with Self Voltage Balancing", IEEE Trans. Ind. Appl., Vol.37, No.2, pp.611-618 (2001).

[9] K. WANG, Y. Li and Z. Zheng: " A new transformerless cascaded multilevel converter topology ", ECCE 2009, pp.3124-3129(2009).

[10] C. WANG and Y.Li : " A Survey on Topologies of Multilevel Converters and Study of Two Novel Topologies ",IPEMC 2009, pp.860-865 (2009).

[11] Y.Suresh and A.K.Panda:'Performance of cascade multilevelH bridge inverter with single DC source by employing low frequency three phase transformers." The 2010 International Power Electronics Conference, pp.495-503.

[12] Keith A, Mike W. Wielebski, Fang Z. Peng,"Control of cascaded multilevel inverters", IEEE Trans.Power Electronics, May 2004.pp732-738

[13] "Multilevel Power Converters" Surin Khomfoi and Leon M. Tolbert, The University of Tennesseepp 324-350.

[14] Anoop Joyti Sahoo, and Rajesh Kumar Tiwari “A Novel Approach for Hiding Secret da ta in Program Files” International Journal of Information and Computer Security. Volume 8 Issue 1, March2016,

[15] Abu Sa lim, Sa chin Tripathi and Rajesh Kumar Tiwa ri “A secure and timestamp-based communication scheme for cloud environment" Published in International Journal of Electronic Security and Digital Forensics, Volume 6, Issue 4, 319-332.

[16] Rajesh Kumar Tiwari and G. Sahoo, "A Novel Watermark Scheme for Secure Relational Databases" Information Security Journal: A Global Perspective, Volume 22, Issue 3, July 2013

[17] "Power Electronics" P.S. Bhimbra, 2nd Edition, Khanna Publishers.pp249-262

[18] "Power Electronics, Circuits Devices and Applications", Muhammad H.Rashid,Third Edition, AcademicPresspp414-425 